\title{
Substandard, falsified and unregistered medicines in Latin America, 2017-2018
}

\author{
Robin Rojas-Cortés ${ }^{1}$
}

Suggested citation Rojas-Cortés R. Substandard, falsified and unregistered medicines in Latin America, 2017-2018. Rev Panam Salud Publica. 2020;44:e125 https://doi.org/10.26633/RPSP.2020.125

ABSTRACT

Objective. To assess all the incidents of substandard, falsified and unregistered medicines in 2017 and 2018 in Latin America, determining the types of products affected, stages of the supply chain in which incidents were detected, quality deviations identified in tested samples, and regulatory measures taken by authorities.

Methods. A comprehensive search of the websites of the Latin American national regulatory authorities was conducted, identifying all eligible incidents during 2017-2018. Standardized values were collected from each incident for pre-determined variables: country, year, type of incident, therapeutic group, supply chain, regulatory measures and laboratory data.

Results. A total of 596 incidents in 13 countries were included (236 substandard, 239 falsified, 116 unregistered and 5 stolen). The therapeutic categories with the highest incidents were: anti-infectives, medicines for pain/palliative care, hormones/contraceptives, medicines for the respiratory tract, and medicines for mental/ behavioural disorders. The most common places where incidents were detected were commercial establishments, pharmacies, health services and manufacturers. The most recurrent quality deviations were failure in parameters (appearance or physicochemical), incorrect labelling, different quantity of active pharmaceutical ingredient, presence of unknown particles, and microbiological contamination. The most frequent regulatory measures identified were alerts, withdrawals, seizures, and prohibition of marketing/distribution/use.

Conclusions. In Latin America, substandard, falsified and unregistered medicines persist as a highly prevalent problem. An advanced degree of regulatory development in countries is associated with higher incident detection/reporting rates and a more comprehensive set of measures. The pharmaceutical supply chain is more vulnerable in its final node. Quality deviations identified in tested samples pose serious risks to public health.

Keywords Counterfeit drugs; substandard medicines; quality control; pharmaceutical preparations; pharmaceutical trade; Latin America.

Substandard, falsified (SF) and unregistered medical products pose a significant threat to public health by undermining the ability to prevent, treat, cure and palliate diseases (1). Such medical products also expose patients worldwide to the harmful effects of undeclared/unauthorized substances, excipients and contaminants. In addition to these deleterious direct public health effects, SF and unregistered medical products may also deteriorate patients' confidence in supply systems and highly strategic interventions such as vaccination campaigns, contribute to antimicrobial resistance (2) and have a substantial negative socioeconomic impact in society $(3,4)$.

Over the last decade, the Pan American Network for Drug Regulatory Harmonization (PANDRH), an initiative of all the National Regulatory Authorities (NRA) of medicines in the Region of the Americas, has actively encouraged its member countries to issue public alerts and warnings when SF incidents

\footnotetext{
1 Regional Network for the Prevention, Detection and Response to Substandard and Falsified Medical Products in the Americas, Washington, DC, United States of America $\triangle$ Robin Rojas-Cortés, rojasedg@paho.org
} 
are detected $(5,6)$; and to report them to the World Health Organization (WHO) Global Surveillance and Monitoring System (GSMS). This system collects incidents from all countries in the world and further supports case investigations and management. The alerts typically provide information on the incidents, what types of medicines are most commonly falsified (i.e., which groups of patients are involved and the level of risk), and at which point of the supply chain they are detected $(7,8)$. Nevertheless, since the reporting mechanism is relatively recent and NRAs must prioritize reporting, usually only high-impact or critical incidents are communicated and, in practice, not all detected cases are sent to the global database.

There is a paucity of research and evidence in this area and no more than a handful of comprehensive multi-country efforts and studies $(1,9-15)$ have described the prevalence of SF and unregistered medicines in specific contexts (e.g., lower-middle-income countries or focusing on a specific type of medicines), making it evident that poor-quality pharmaceuticals are a substantially understudied problem (16). Many studies and reports, however, note that a better understanding of the public health impact of these products and the magnitude of the problem is a key element when advocating governments to invest in strengthening their medicines regulatory capacities $(9,16,17)$.

The regulatory capacity in the Americas widely varies and NRAs have different degrees of development and enforcement capacities. Some of the reasons include lack of harmonized procedures, definitions and training; shortage of human resources and appropriate competencies to address regulatory challenges; and lack of infrastructure/information systems $(8,18)$.

The present work assesses all the incidents of SF and unregistered medicines published by Latin American NRAs between 2017 and 2018. Additionally, it determines the types of products that were most frequently affected in the Region, the different stages of the supply chain in which they were most commonly detected, the most frequent types of quality deviations identified in tested samples, and the main regulatory measures taken by NRAs when addressing these incidents.

\section{METHODS}

\section{Data search}

A comprehensive search of the websites of the NRAs of medicines was conducted in each of the 19 Spanish or Portuguese speaking countries in Latin America, compiling all the public alerts, warnings or advisories issued from January 12017 to December 312018 regarding incidents of SF, unregistered or stolen medicines. All websites were explored to identify the sections where this information was published, and all records were screened manually for inclusion and exclusion criteria.

\section{Inclusion criteria}

- Incidents where information provided at least minimum data that allows: a) classifying the product as a medicine, b) identifying the specific name of the product and active pharmaceutical ingredient (API), c) identifying or determining if the product was SF, unregistered or stolen, and d) classifying the product by a therapeutic group.
- Incidents identified -either through active or passive surveillance- within the national territory of the country that issued the alert/warning/advisory.

- Incidents identified through information received from an international organization or another country, affecting a product proven to be present in the market of the country issuing the alert/warning/advisory.

Details on handling of individual categories and specific products can be obtained from the author upon request.

\section{Exclusion criteria}

- Incidents involving products that either were or were advertised as natural, herbal, phytotherapeutics, dietary supplements, food, cosmetics, hygiene products, sanitizing agents or household cleaning products.

- All alerts/warnings/advisories replicated from (or issued based on) information received from international organizations or other countries, without evidence suggesting that the product was present in the national territory.

- Ambiguous statements alerting, recalling or withdrawing the product without explicitly mentioning that it was SF, unregistered or stolen.

- Products that advertised to have therapeutic effects (e.g., to gain strength) but were not medicines.

- Products that only declared to contain herbal ingredients, even if they later proved to contain an API.

- Incidents regarding medical supplies (e.g., bulk raw materials).

- All incidents where websites, links or related documents were corrupted, damaged or not available to extract information on the case.

- All alerts and information regarding the global issue of substandard valsartan and other medicines contaminated with nitrosamines (in order not to mask the trends identified).

\section{Data collection}

A data collection format was developed in Microsoft ${ }^{\circledR}$ Excel, and the following variables from all eligible incidents were extracted, when available:

- "Country" and "Year" where incident occurred.

- Name of the "Product" involved.

- "Type of incident" according to the WHO definitions for "substandard", "falsified" or "unregistered" medical products (1). Additionally, the category "stolen" was added, since products that leave the legal supply chain may re-enter it at a later stage as falsified or substandard versions.

- "Therapeutic group".

- Point of the "Supply Chain" where it was detected.

- "Laboratory data" on quality deviations identified in the samples.

- "Regulatory measures" taken by the NRA.

\section{Data analysis}

Since terminology among countries is not harmonized, the description of the incident permitted to classify it as "substandard", "falsified", "unregistered" or "stolen". The unit of 
analysis considered for the present work was the "incident", which was defined as a case of a single SF, unregistered or stolen medicine that was published in any sort of public communication by the NRA on its website, either alone or together with other products.

The variable "Therapeutic group" was the main indication of the product according to the categories adopted by the $21^{\text {st }}$ WHO Expert Committee on the Selection and Use of Essential Medicines (19). Two additional categories were added: "Homeopathic" and "Other".

Furthermore, the variable "Supply chain" included the following options: manufacturer, wholesaler, distributor, pharmacy, health service (i.e., hospital, clinic, etc.), patient, store/drugstore/market, offer through internet, other, and not available.

The variable "Laboratory data" collected information on the type of quality deviations that were identified whenever laboratory analyses were done to samples (e.g., incorrect labelling, microbiological contamination, or failure in the physicochemical/appearance parameters, among others).

The variable "Regulatory measures" included the decisions that the NRAs took after identifying the incidents (e.g., issue of public alerts, prohibition of marketing/distribution/use, seizure of affected products, destruction of samples, among others).

\section{RESULTS}

A total of 23 sections of 15 websites from the NRAs of medicines of 15 Latin American countries were systematically searched for alerts, warnings, communications or advisories meeting the inclusion criteria. At the moment when searches were conducted (16 June, 2019), the NRAs of the Dominican Republic, Nicaragua, Paraguay and Uruguay did not have a website where incidents of SF and unregistered products were published. Table 1 presents the classification of such events, by country. Data is presented in terms of whether or not the incidents were related to a country where there is an NRA of Regional Reference (NRAr). As defined by the Pan American Health Organization/World Health Organization, a NRAr is one that has been assessed and has obtained the highest level of achievement of a series of critical indicators that reflect the WHO's recommendations for regulatory bodies (20).

Based on eligibility (inclusion) criteria, a total of 596 incidents in 13 countries were included in this study. Cuba and Guatemala had no incidents meeting the inclusion criteria. A total of 236 incidents were related to substandard products, 239 to falsified ones, 116 to unregistered ones and 5 to stolen ones. Countries with the highest numbers of reports were Peru (30.8\%; $\mathrm{N}=184)$, Brazil (28.5\%; $\mathrm{N}=170)$, Chile $(9.8 \% ; \mathrm{N}=59)$ and Colombia $(9.8 \% ; \mathrm{N}=59)$. Only 5 incidents $(0.8 \%)$ of stolen medicines were registered in the Region. Among countries that do not have a NRAr, Peru had a high number of incidents regarding falsified products $(\mathrm{N}=171)$, which considerably differs from other countries in the same category, which had a range from 0 to 19 cases in total.

Figure 1 presents the total eligible incidents, by therapeutic group. The therapeutic categories with the highest incidents were: anti-infective medicines $(16.7 \% ; \mathrm{N}=100)$, medicines for pain and palliative care $(14.2 \%$; $\mathrm{N}=85)$, hormones, other endocrine medicines and contraceptives $(9.5 \%$; $=57)$, medicines acting on the respiratory tract $(6.0 \% ; \mathrm{N}=36)$, medicines for

TABLE 1. Total eligible incidents of substandard, falsified, unregistered and stolen medicines in Latin America (2017-2018), by country

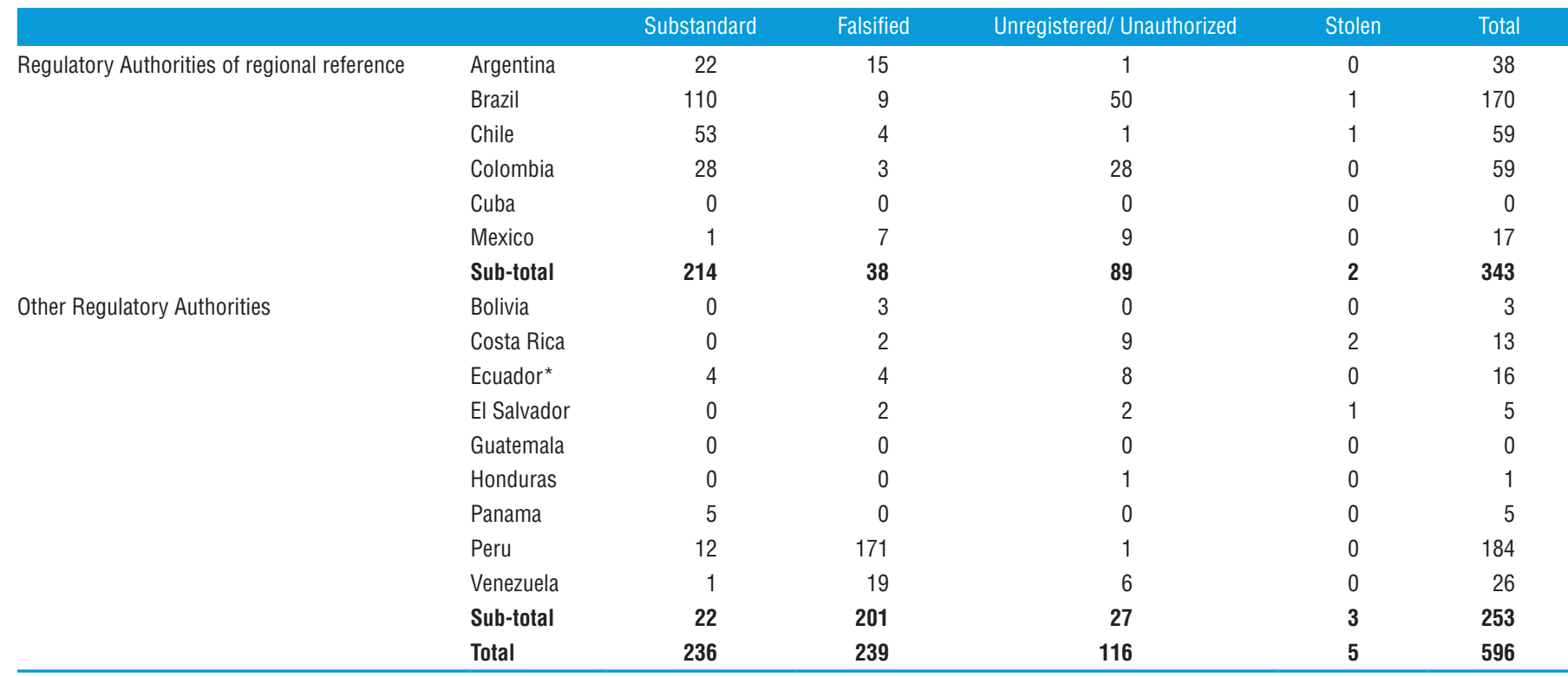

Notes: Table prepared by the author from data published in the following NRA websites. Argentina: https://www.argentina.gob.ar/anmat/alertas/medicamentos; http://www.anmat.gov.ar/alertas_medicamentos.asp; https://www.argentina. gob.ar/anmat/alertas/productosmedicos; http://www.anmat.gov.ar/alertas_productos_medicos.asp; Bolivia; http://agemed.minsalud.gob.bo/vigilancia/alert-ilici. htm (site not available anymore, due to an update to a new domain); Brazil http://portal.anvisa.gov.br/produtos-irregulares\#/; Chile: http://www.ispch.cl/category/categorias-comunicado/alertas-sanitarias/retiro-de-medicamentos; http://www.ispch.cl/buttons/docs/Listado\%20de\%20productos\%20con\%20 resol\%20prohibicion\%20uso\%20y\%20distribucion\%20para\%20web.xlsx; Colombia: https://app.invima.gov.co/alertas/medicamentos-productos-biologicos; Costa Rica: https://www.ministeriodesalud.go.cr/index.php/alertas/alertapor-productos-en-el-mercado; Cuba: https://www.cecmed.cu/vigilancia/alertas; https://www.cecmed.cu/vigilancia/notas-informativas; Ecuador: https://www.controlsanitario.gob.ec/category/notialertas/alertas-arcsa-medicamentos/; El
Salvador: https://www.medicamentos.gob.sv/index.php/es/servicios-m/ciudadanos/alertas-dnm/alertas-sanitarias; https://www.medicamentos.gob.sv/index.php/es/servicios-m/ciudadanos/alertas-dnm/alertas-sanitarias-internacionales; https://www.medicamentos.gob.sv/index.php/es/servicios-m/ciudadanos/alertas-dnm/alertas-nacionales-historial; Guatemala: https://medicamentos.mspas.gob.gt/index.php/alertas/comunicado-a-medicos-prescriptores; Honduras: http:// www.arsa.gob.hn/index.php?page=alertas; Mexico: https://www.gob.mx/cofepris/documentos/alertas-sanitarias-de-medicamentos; https://www.gob.mx/cofepris/documentos/alertas-sanitarias-de-otros-productos-y-servicios; Panama: http://www.minsa.gob.pa/informacion-salud/alertas-y-comunicados?title=\&field_decree_date_value $\% 5$ Bvalue $\% 5 \mathrm{D} \% 5 \mathrm{Byear} \% 5 \mathrm{D}=;$; Peru: www.digemid.minsa.gob.pe/main.asp?Seccion=371; Venezuela: http://www.inhrr.gob.ve/alertas ce.php. Data includes incidents reported between January 2017 and December 2018 . For full inclusion criteria, please refer to Methods section. At the moment when searches were conducted (16 June, 2019 ), the NRAs of the Dominican Republic, Nicaragua, Paraguay and Uruguay did not have a website where incidents of SF and unregistered products were published. *Data from Ecuador is only available for 2018. 
FIGURE 1. Total eligible incidents of substandard, falsified, unregistered and stolen medicines in Latin America (2017 - 2018), by therapeutic group

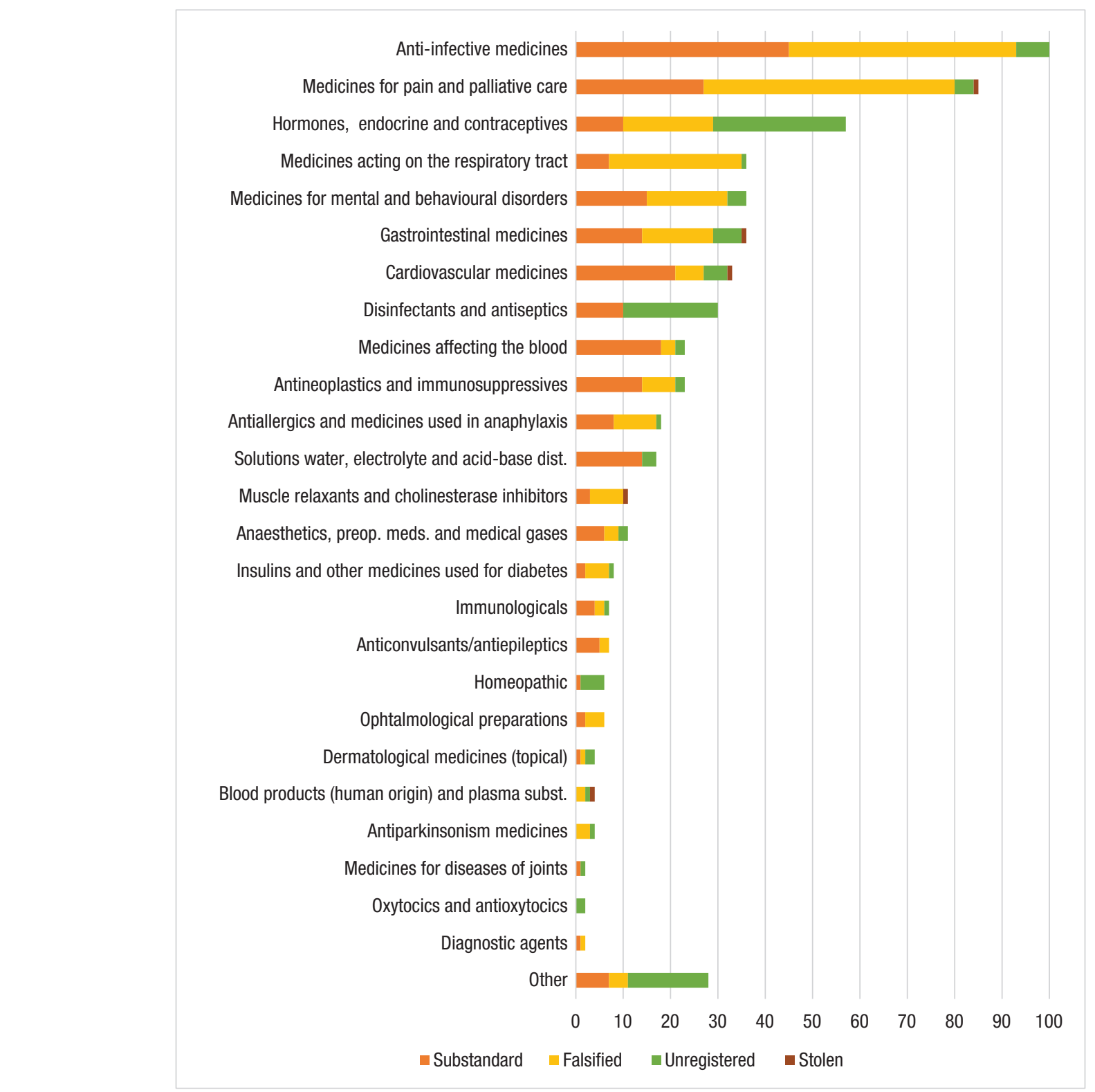

Notes: Figure prepared by the author from data published in the NRA websites detailed in Table 1. Data includes incidents reported between January 2017 and December 2018 . Total number of incidents $=596$. For full information on group classification please refer to Methods section.

mental and behavioural disorders" $(6.0 \% ; \mathrm{N}=36)$, and gastrointestinal medicines $(6.0 \% ; \mathrm{N}=36)$. Noticeably, the cases in the first three categories accounted for $40.6 \%$ of all 596 incidents compiled. Among all top categories, the majority of cases were either substandard or falsified; with the exception of "hormones, other endocrine medicines and contraceptives", in which the incidents of unregistered products accounted for half $(49.1 \% ; \mathrm{N}=28)$ of the total.

There was a tendency to not report data on the different stages of the supply chain where incidents were detected. Of all 596 incidents eligible for the analysis, 54.8\% ( $\mathrm{N}=327)$ did not have any information on this regard. Among incidents that did report this variable, Figure 2 shows the corresponding proportions for each stage of the supply chain, as well as the absolute number of detections per country (an incident may have been detected at more than one stage).

The most common places where incidents were detected ( $46.0 \%$; $\mathrm{N}=156$ ) were shops/drugstores/markets, largely due to incidents of falsified products in Peru that accounted for $98.7 \%$ $(\mathrm{N}=154)$ of cases in this individual category and that were sold in this type of facilities. Besides, pharmacies (retailers) and health services, such as hospitals or clinics, as well as manufacturers, were also identified as common places where SF and unregistered products were present in countries.

In terms of the variable "laboratory data" (that examines the quality deviations that were identified in the samples tested) Table 2 describes the findings on available data by the ten top therapeutic groups affected and the type of incident. Of all 596 
FIGURE 2. Stages of the supply chain where incidents of substandard, falsified, unregistered or stolen products were detected in Latin America (2017-2018), including individual detections by country

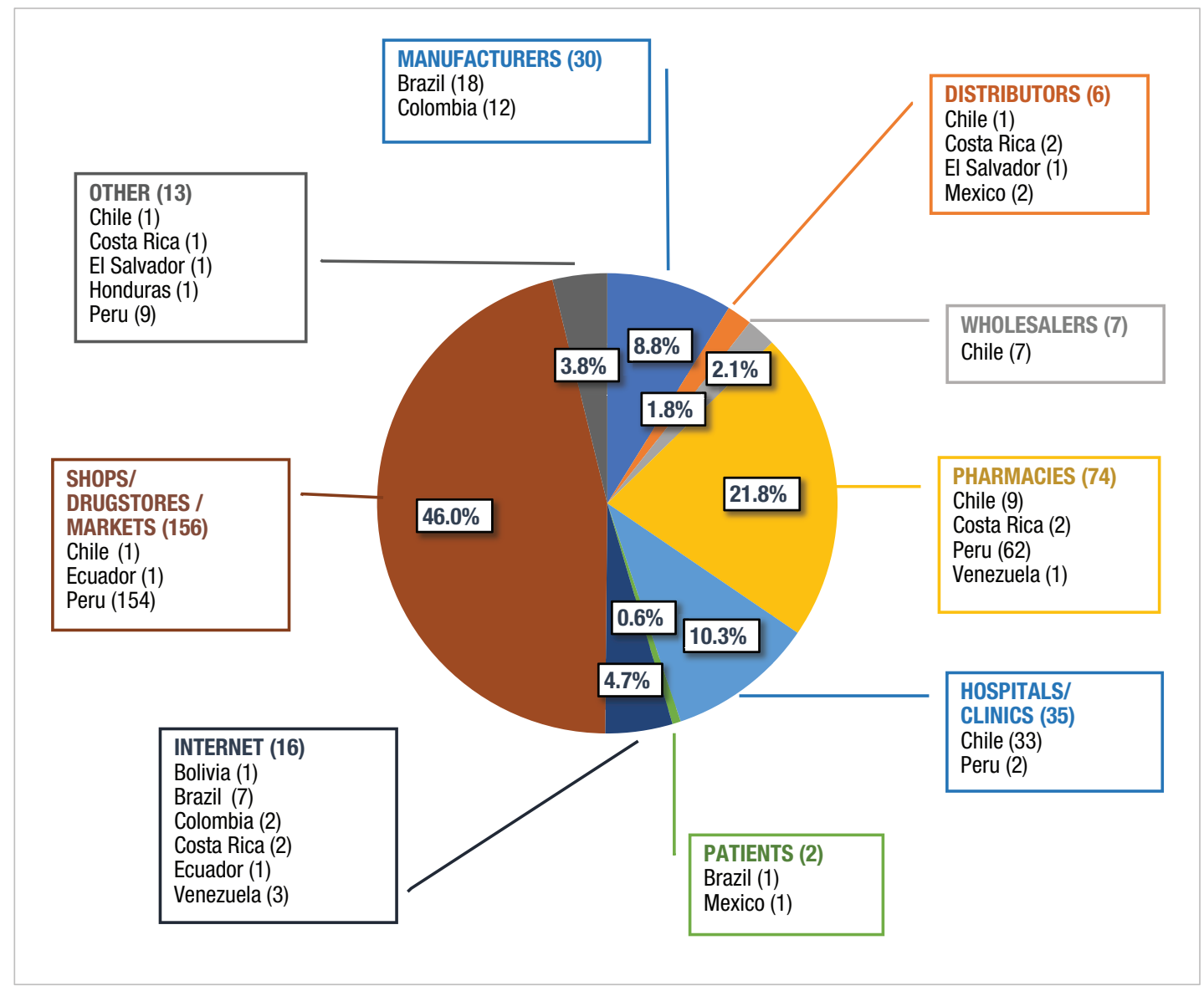

Notes: Figure prepared by the author from data published in the NRA websites detailed in Table 1. Data includes incidents reported between January 2017 and December 2018. Total number of detections $=339$ Individual incidents may have been detected at more than one stage of the supply chain. Percentages are calculated based on the total number of detections at different stages of the supply chain. Cases where this information was not reported were not taken into consideration for this section of the analysis. At the moment when searches were conducted (16 June, 2019), the NRAs of the Dominican Republic, Nicaragua, Paraguay and Uruguay did not have a website where incidents of SF and unregistered products were published.

eligible incidents, only $40.1 \%(\mathrm{~N}=239)$ reported details on the type of quality deviations that products presented. Percentages were calculated based on the total number of quality deviations identified. Cases where information on this variable was not reported were not taken into consideration for this section of the analysis. The quality deviations most commonly identified were: failure in parameters (appearance or physicochemical) $(30.2 \%$; $\mathrm{N}=79)$, incorrect labelling $(18.7 \% ; \mathrm{N}=49)$, different quantity of or no active pharmaceutical ingredient (API) $(12.2 \%$; $\mathrm{N}=32)$, presence of unknown particles $(11.1 \% ; \mathrm{N}=29)$ and microbiological contamination $(8.0 \% ; \mathrm{N}=21)$. The reporting rate of this variable was very low among falsified and unregistered products; and considerably high in the case of substandard products.

Table 3 shows the ten most common regulatory measures that were contained in the alerts from eligible incidents. The "public alert" was, by far, the most commonly adopted measure among all authorities (all eligible incidents were extracted from a regulatory document published by the NRA). Of all 1793 regulatory measures identified in 13 countries, $72.5 \%$ $(\mathrm{N}=1301)$ were issued by five of the six NRArs.

Measures such as withdrawal/recall of the affected products, seizure/confiscation, prohibition of marketing, prohibition of distribution and prohibition of use; were also frequently used by countries. Brazil was the country with the highest number of regulatory measures $(41.1 \% ; \mathrm{N}=737)$. These figures were directly related to the number of incidents detected. Brazil and Colombia were the only countries that consistently used at least eight of the ten main types of measures. As per the information available, Brazil was the only country in the region implementing the prohibition of advertising; Colombia was the only one to request local stakeholders to monitor adverse events following the use of affected products (pharmacovigilance); and Brazil, Colombia and Peru were the only cases where a destruction of the affected products was specifically ordered.

\section{DISCUSSION}

\section{Frequency and distribution of incidents}

Our findings suggest that the issue of SF and unregistered medicines in Latin America is a problem of great magnitude. Based on the published data of detected incidents, it appears that five out of the six NRArs (Argentina, Brazil, Chile, Colombia and Mexico) considerably detect and communicate the highest proportion of incidents in the Region. The existence of NRArs, therefore, may indicate higher regulatory development as well 
TABLE 2. Quality deviations in tested samples of substandard, falsified, unregistered and stolen medicines in Latin America (20172018), by therapeutic group and by type of incident

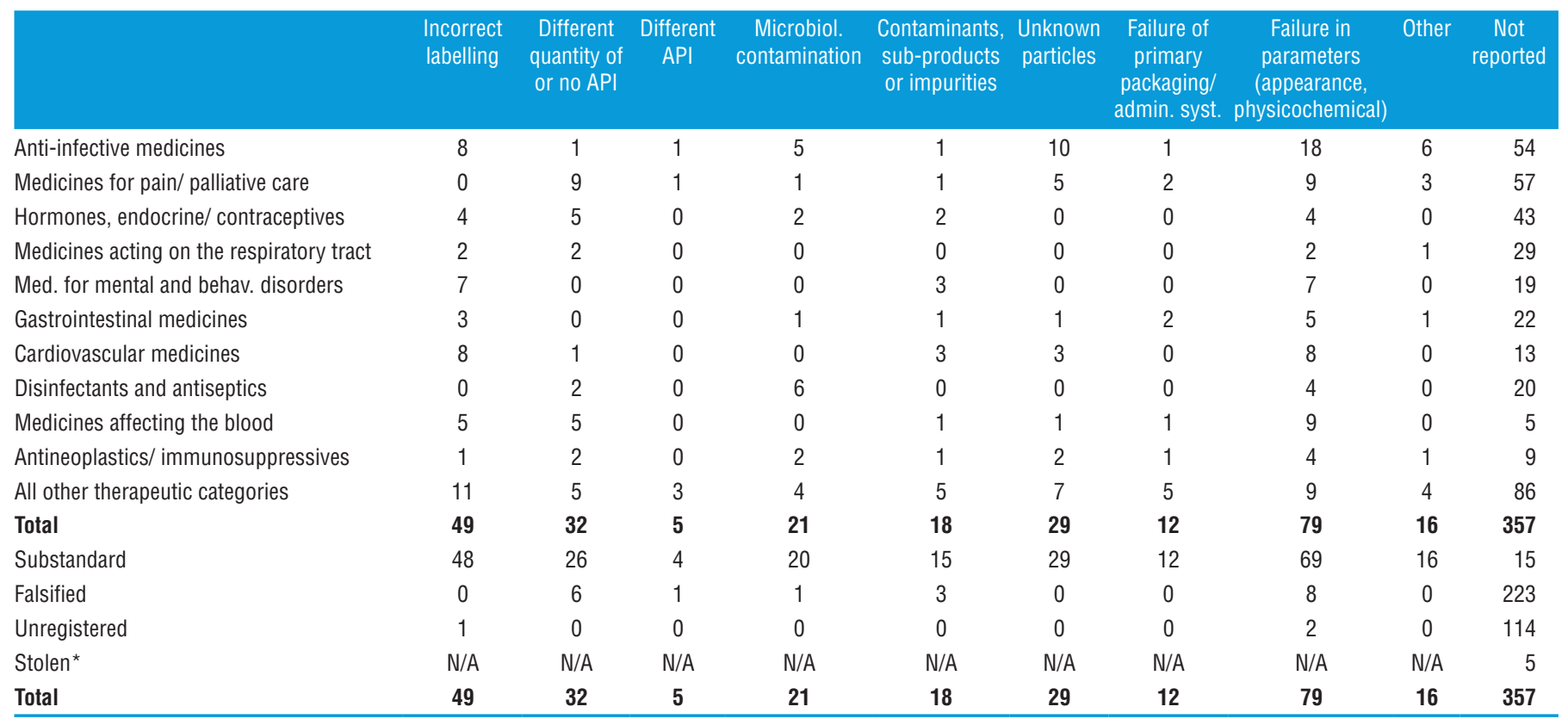

Notes: Table prepared by the author from data published in the NRA websites detailed in Table 1. Data includes incidents reported between January 2017 and December 2018 . Total number of quality deviations identified $=261$. Individual incidents sometimes presented more than one quality deviation. API $=$ Active Pharmaceutical Ingredient, Microbiol. $=$ Microbiological, admin. syst. $=$ administration system, Not. rep. $=$ Not reported, Med. $=$ Medicines,
behav. $=$ behavioral. ${ }^{*}$ Quality control analyses cannot be done on stolen samples since they are missing by definition: they are reported as N/A = Not available.

TABLE 3. Regulatory measures taken by Latin American Medicines Authorities on incidents of substandard, falsified, unregistered or stolen products (2017-2018), by country and by type of incident

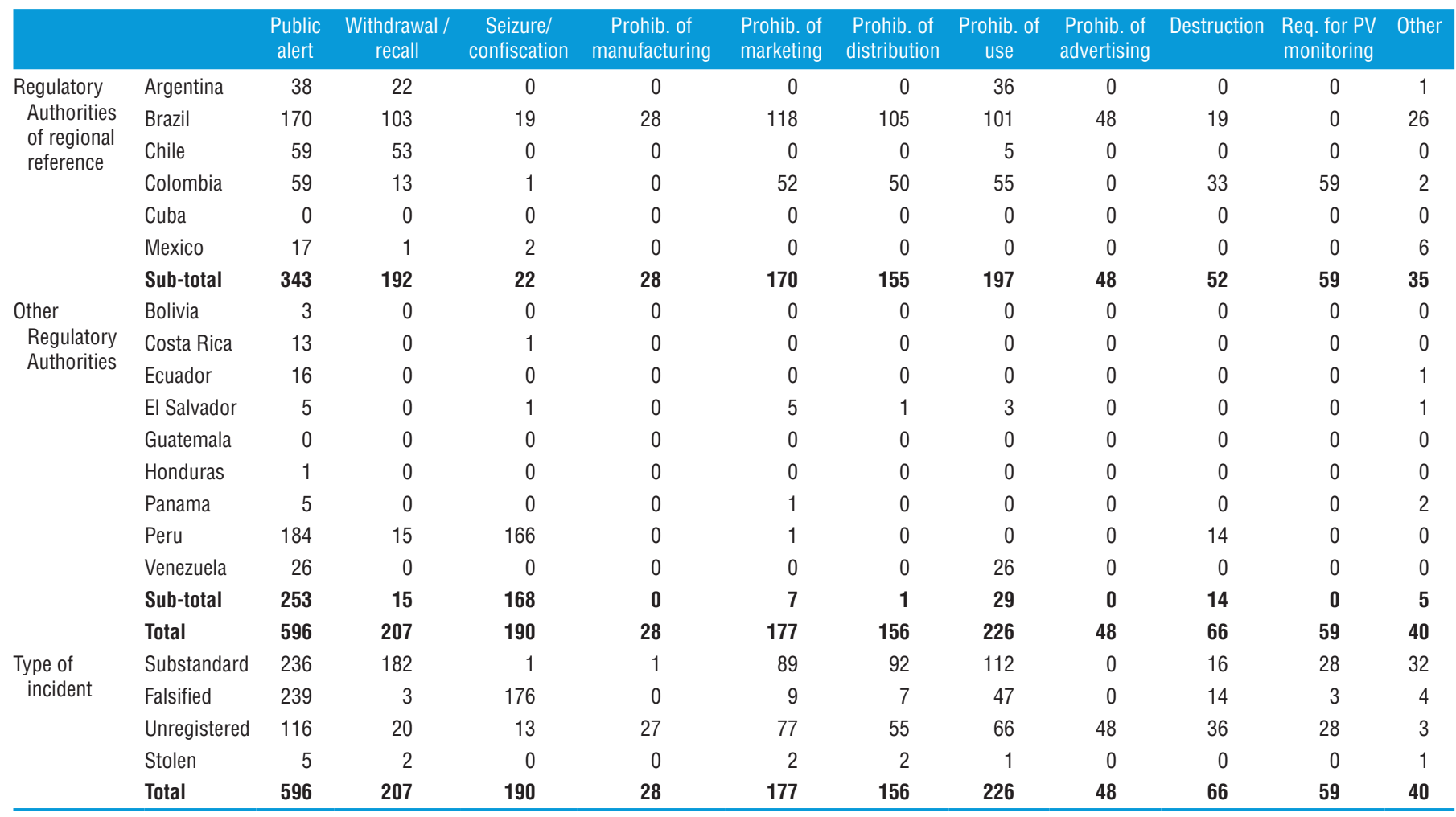

Notes: Table prepared by the author from data published in the NRA websites detailed in Table 1. Data includes incidents reported between January 2017 and December 2018 . Total number of regulatory measures indentified $=1793$. NRAs sometimes issued more than one regulatory measure per incident. MA = Marketing Authorization, Prohib. = Prohibition, Req. = Request, PV = Pharmacovigilance. At the moment when searches were conducted (16 June, 2019), the NRAs of the Dominican Republic, Nicaragua, Paraguay and Uruguay did not have a website where incidents of SF and unregistered products were published. 
as better capacity to conduct market surveillance, thus resulting in higher rates of detection of SF and unregistered products. Additionally, local stakeholders, such as customs authorities, wholesalers, distributors, hospitals, pharmacies or even patients and health professionals in countries with NRArs may be more conscious of their role in reporting suspected incidents to the health authorities due to public communications or awareness initiatives led by the NRA. Since most NRArs were created at least 20 years ago, there appears to be a positive relation between maturity of the regulator and detection rate of incidents. This statement should be interpreted with caution, however, since other sources state that high numbers of reports depend not only on the maturity of the NRA, but also on the susceptibility of the country's market to the penetration of SF and unregistered products (21). Cuba, the remaining NRAr, has a particular pharmaceutical market with no private production/distribution and has identified the same absence of incidents in other works (22).

The overall proportion of substandard and falsified incidents was very similar, but this similarity arises mainly due to the high number of falsified incidents reported in Peru. There is a high proportion of non-pharmaceutical, informal and clandestine establishments in Peru where falsified medicines have been found (23). In the last few years, the Peruvian NRA has conducted large police operations and massive seizures in high risk zones of different cities, targeting specific shopping centres where falsified products were sold (24). However, setting this case aside, the proportion of substandard products is generally higher than that of falsified products.

\section{Therapeutic groups of medicines}

The therapeutic categories of medicines that are most commonly SF or unregistered give an idea of the groups of patients who are at higher risk to consume them. Among these categories, anti-infective medicines had the highest frequency of incidents (of all types). Although antibiotics and other antimicrobials should only be dispensed to or purchased by patients who have valid prescriptions, this is hardly the case in practice. In the Americas alone, one study found that $88 \%$ of countries, despite existing regulations, dispense antibiotics without a prescription (25). Many medicines for pain/palliative care, and those acting on the respiratory tract (which were ranked, after anti-infectives, as the second and fourth most common groups of medicines with incidents of SF or unregistered units, respectively) often include over-the-counter products, so patients may get direct access to these medications if they choose to.

A particularly concerning issue regarding the high number of incidents of SF anti-infective medicines is the impact that these products have on the development of antimicrobial resistance (26). Patients who receive suboptimal doses of an antimicrobial for the treatment of an infection may experience a therapeutic failure and may contribute to the development of drug resistance in the microorganism (27). At the populational level, this situation has an important impact on higher morbidity and mortality indicators, loss of patient confidence in the health system, and a waste of valuable economic resources (1).

The findings of this study in terms of the main therapeutic categories involving incidents in the Region are consistent with the data collected by the Global Surveillance and Monitoring System. Based on all reports from countries between 2013 and 2017, the System reported that anti-infective medicines (antibiotics, HIV/hepatitis medicines and malaria medicines) and medicines for pain management (anaesthetics and painkillers) were the two most frequent therapeutic groups with SF incidents worldwide (21). Other studies have also found anti-infectives to be the most affected type of medicines (12).

The last therapeutic category among the top four most frequent ones is "hormones, endocrine and contraceptives". In this group, there was a considerable number of incidents involving anabolic and androgenic steroids (many of which were found to be unregistered), as well as contraceptives. Steroids are commonly misused by those wishing to increase muscle mass, lose weight and/or increase physical performance. However, the use of these drugs often leads to serious adverse effects that are both physical and psychological and can easily cause addiction (28). In addition, poor-quality contraceptives, especially those containing a suboptimal dose of the API, may lead to therapeutic failures (i.e., unintended pregnancies).

\section{Stages of the supply chain where incidents were detected}

The vast number of players in supply chains (i.e., suppliers of raw materials, manufacturers, wholesalers, pharmacies, hospitals, health care providers and patients) makes products more vulnerable to a considerable number of threats that may affect their safety, quality and efficacy (29).

Detection was most common in stores/drugstores/markets, pharmacies and hospitals/clinics. In these three types of facilities, that account for $78.1 \%$ of all the documented detections, medicines were ready to be sold, dispensed or administered to patients. This finding supports the hypothesis that the supply chain is most vulnerable in its final node, and SF and unregistered medical products may enter it more easily. As a medicine moves towards the patient along the product life cycle, the number of regulatory controls decreases, while the number of stakeholders and transactions increases (21).

This study found a relatively low proportion of SF and unregistered medicines sold by the internet or social media $(4.7 \%)$. However, as previously highlighted, this study does not capture information on the dietary supplements (e.g., vitamins, minerals, botanicals, amino acids, among others) and other products that advertise therapeutic properties (e.g., sexual enhancement, weight loss, glycaemic control, etc.) that are not technically medicines but are frequently sold online. Additionally, the detection and response to internet sales of medical products is a common major challenge among all NRAs.

\section{Quality deviations}

Although there are no standardized classifications of quality deviations of pharmaceutical products (30), we grouped the most common types of results found among eligible incidents, when NRAs analysed samples of products out of specifications. These findings came from active surveillance programmes that monitor the quality of medicines in the market, from investigation of reports of incidents made by the public (or other stakeholders) and from routine analyses conducted by manufacturers or marketing authorization holders on their own products.

Among products that reported information on this variable, quality deviations such as failure in physicochemical parameters, incorrect labelling, different quantities of or no API, 
presence of unknown particles and microbiological contamination, are highly concerning. All of them may compromise the efficacy and/or safety of the product. Alterations in physicochemical parameters may range from organoleptic changes to stability issues of the API or excipients. Some of these components may, due to environmental reasons, suffer degradation leading to either inactive or toxic agents. Another concerning deviation is incorrect labelling, which may mislead patients to the administration of wrong drugs, the use of higher or lower doses than required, or even the intake of expired products. Different quantities of or no API may either lead to therapeutic failures or to intoxication/poisoning. Lastly, microbiological contamination may lead to infectious processes when administered to individuals. According to this study, however, these types of quality deviations did not affect a specific therapeutic group of medicines. These considerations regarding the type of disease treated, the intended route of administration, or even the environmental conditions in which a product is stored in the field, give an idea of the potential impact of substandard medicines in public health. Strengthening of post-market surveillance, including inspections and testing of samples, is critical to timely identify substandard products before they reach patients.

\section{Regulatory measures}

NRAs must have the necessary legal provisions or mandates, mechanisms and resources to conduct effective surveillance of the pharmaceutical market and to further intervene (i.e., take the corresponding actions) when non-compliance is detected in marketed products.

Since each incident in this study was extracted from information contained in public alerts, advisories or warnings, these were the regulatory measures with the highest prevalence. The alerts are, per se, a key regulatory decision that NRAs take to warn the public about a problem with a product on the market. Other significantly prevalent measures were withdrawal/recall of the affected products, seizure/confiscation, and prohibition of marketing, distribution and use.

As seen throughout this study, alerts do not always contain all the information necessary to characterize, manage, and ultimately minimize an identified risk related to an SF or unregistered product. The gaps in access to information highlight the need for a coordinated multi-stakeholder approach to address this problem, in which every actor and authority has clearly defined roles, timelines and communication channels and procedures.

There appears to be a direct relation between the number of regulatory measures taken and the presence of an NRAr in a country. According to our data, NRArs issue a more comprehensive set of measures when addressing incidents.

\section{Limitations of this study and recommendations for regulators}

Limitations of this study include the fact that the reports are based only on published data of detected incidents, and detection generally depends on the degree of development of the regulatory system. Countries sometimes do not publish the information on incidents, either because the details of the cases are incomplete or for other reasons. Additionally, reports not always state if the incident was detected based on active surveillance or spontaneous reports. Furthermore, the real dimension of the illicit market of medicines (i.e., the cases that evade regulatory controls), due to its clandestine nature, is still unknown. Illegal sexual enhancers and products for weight loss were not included in the analysis. These products, which often contain undeclared ingredients and are advertised alleging unproven therapeutic properties, are highly prevalent in the Region. Lastly, another limitation of the information collected is the possibility that countries issued regulatory measures after the original alerts/warnings were published, and these were not captured.

Regulatory controls should target all stages of the supply chain to ensure that authentic, safe, efficacious and quality medicines produced by licensed manufacturers are the same ones that patients receive and consume. Comprehensive sets of measures, strong enforcement capacities and international collaboration are required to effectively prevent, detect and respond to SF incidents. Standardization among countries of fields/basic information regarding the SF incidents that must be included in public alerts may facilitate a common understanding among stakeholders of the risks involved and the actions that must be taken. A field needing further study is the dimension and public health impact of SF natural, herbal, phytotherapeutics, dietary supplements, food, cosmetics, hygiene products, sanitizing agents and household cleaning products. Actual implementation of NRA measures/decisions by stakeholders is another area that would benefit from additional research.

\section{CONCLUSIONS}

According to the data collected from 2017 to 2018, in Latin America SF and unregistered medicines persist as a highly prevalent public health problem. An advanced degree of regulatory development in countries (i.e., the existence of a NRAr) is associated with higher incident detection/reporting rates, as well as with a more comprehensive set of regulatory measures taken in response to incidents. Our findings are consistent with the global data collected by the WHO Global Surveillance and Monitoring System in terms of the most frequently affected therapeutic categories of products. Results also highlight the vulnerability of the pharmaceutical supply chain towards its end, where the products are about to be dispensed or administered to patients. Quality deviations identified in tested samples pose significant risks for the health of patients that range from lack of efficacy to toxic effects. NRAs should allocate sufficient resources, strengthen their enforcement capacities and collaborate among each other at regional/global levels to appropriately prevent, detect and respond to SF medical products.

Author contributions. Robin Rojas-Cortés conceived the original idea; collected and analyzed the data; interpreted the results; and wrote, reviewed and approved the final version of the paper.

Acknowledgments. The author thanks José Luis Castro and Alexandra Guta at the Pan American Health Organization and Emma Richards at the University of Essex for their valuable feedback on the analysis and manuscript.

\section{Conflicts of interest. None declared.}

Disclaimer. Author holds sole responsibility for the views expressed in the manuscript, which may not necessarily reflect the opinion or policy of the RPSP/PAJPH and/or PAHO. 


\section{REFERENCES}

1. World Health Organization. A study on the public health and socioeconomic impact of substandard and falsified medical products. Geneva: WHO; 2017. Available from: https://www.who.int/ medicines/regulation/ssffc/publications/SE-Study_EN_web. pdf?ua=1 Accessed 4 May 2020.

2. Suthar A, Coggin W, Raizes E. Antimicrobial resistance and substandard and falsified medicines: the case of HIV/AIDS. J Infect Dis. 2019;219(4):672-673.

3. The World Bank. Pharmaceuticals: counterfeits, substandard drugs and drug diversion. The World Bank; 2005. Available from: http:// documents.worldbank.org/curated/en/320051468135938535/ pdf/321920HNPBrief120Pharmeceuticals.pdf Accessed 9 March 2019.

4. Institute of Medicine. Countering the problem of falsified and substandard drugs. Washington: The National Academies Press; 2013.

5. Red Panamericana para la Armonización de la Reglamentación Farmacéutica. Pautas a ser consideradas por las autoridades de salud ante una sospecha de falsificación de productos médicos. Washington: Organización Panamericana de la Salud; 2013.

6. Bolaños R, Bond K, Child R, Coto J, Cummings R, Dellepiane N, Fitzgerald J, Parker C, Pereira P, Sánchez y Tépoz J, Stergachis A. Improving safety, quality and efficacy of medicines in the Americas. Rev Panam Salud Pública. 2016;39(5):215-216.

7. Organización Panamericana de la Salud. Propuesta de programas nacionales de prevención de la falsificación de medicamentos y plan de acción (road map). OPS; 2013. Available from: https:// www.paho.org/hq/dmdocuments/2013/GCFM-RutaCritica-1.pdf Accessed 18 September 2020.

8. Pombo M, Porrás A, Saidón P, Cascio S. Regulatory convergence and harmonization: barriers to effective use and adoption of common standards. Rev Panam Salud Pública. 2016;39(5):217-225.

9. Kaur H, Clarke S, Lalani M, Phanouvong S, Guérin P, McLoughlin A, Wilson B, Deats M, Plançon A, Hopkins H, Miranda D, Schellenberg D. Fake anti-malarials: start with the facts. Malaria J. 2016;15(86) doi: https:/ / doi.org/10.1186/s12936-016-1096-x

10. Ozawa S, Evans D, Bessias S, Haynie D, Yemeke T, Laing S, Herrington J. Prevalence and estimated economic burden of substandard and falsified medicines in Low- and Middle-Income Countries. JAMA Netw Open. 2018;1(4):e181662.

11. Nayyar G, Breman J, Newton P, Herrington J. Poor-quality antimalarial drugs in southeast Asia and sub-Saharan Africa. Lancet Infect Dis. 2012;12:488-496.

12. Mackey T, Liang B, York P, Kubic T. Counterfeit Drug Penetration into Global Legitimate Medicine Supply Chains: A Global Assessment. Am J Trop Med Hyg. 2015;92(Suppl 6):59-67.

13. Bate R, Coticelli P, Tren R, Attaran A. Antimalarial Drug Quality in the Most Severely Malarious Parts of Africa - A Six Country Study. PLoS One. 2008;3(5):e2132.

14. Hajjou M, Krech L, Lane-Barlow C, Roth L, Pribluda V, Phanouvong S, El-Hadri L, Evans L, Raymond C, Yuan E, Siv L, Vuong T, Boateng K, Okafor R, Chibwe K, Lukulay P. Monitoring the Quality of Medicines: Results from Africa, Asia, and South America. Am J Trop Med Hyg. 2015;92(Suppl 6):68-74.

15. Sabartova J, Toumi A, Ondari C. Survey of the quality of selected antimalarial medicines circulating in six countries of sub-Saharan Africa. Geneva: World Health Organization; 2011.

16. Mackey T. Prevalence of substandard and falsified essential medicines. JAMA Netw Open. 2018;1(4):e181685.
17. World Health Organization. A proposal for a study on the public health and socioeconomic impact of substandard/spurious/ falsely-labelled/falsified/counterfeit (SSFFC) medical products. Geneva: WHO; 2015. Available from: https://apps.who.int/gb/sf/ pdf_files/MSM4/A_MSM4_6-en.pdf Accessed 4 May 2020.

18. Pombo M, Di Fabio J, Cortés M. Review of regulation of biological and biotechnological products in Latin American and Caribbean countries. Biologicals. 2009;37(5):271-276.

19. World Health Organization. The Selection and Use of Essential Medicines: Report of the WHO Expert Committee 2017. Geneva: WHO; 2017.

20. Pan American Health Organization [Internet]. System for evaluation of the National Regulatory Authorities for Medicines. 2018. Available from: https://www.paho.org/hq/index.php?option= com_content\&view=article\&id=1615:2009-sistema-evaluacionautoridades-reguladoras-nacionales-medicamentos\&Itemid= 1179\&lang=en Accessed 30 June 2019.

21. World Health Organization. WHO Global Surveillance and Monitoring System for Substandard and Falsified Medical Products. Geneva: WHO; 2018.

22. Hevia R, Hernández A, Mederos A, Robaina R. Vigilancia de medicamentos fraudulentos desde la unidad de información y vigilancia de medicamentos. In: Convención Internacional de Salud, Havana, 2018.

23. Asociación Nacional de Cadenas de Boticas. Medicamentos ilegales en el Perú: Diagnóstico de la situación y recomendaciones de política. Lima: ANACAB; 2019.

24. Dirección General de Medicamentos, Insumos y Drogas [Internet]. DIGEMID destruye 15 toneladas de medicamentos ilegales incautadas en operativos. 2018. Available from: http://www.digemid. minsa.gob.pe/Main.asp?Seccion=3\&IdItem=2149 Accessed 7 July 2019.

25. Organismo Andino de Salud, Organización Panamericana de la Salud. Estrategia Andina de uso racional de medicamentos y otras tecnologías sanitarias y plan de acción. Lima: ORAS/CONHU; 2015.

26. Ravinetto R, Dujardin C. The threat of poor quality antibiotics in increasing antimicrobial resistance. BMJ. 2016;354:i3618.

27. Kelesidis T, Kelesidis I, Rafailidis P, Falagas M. Counterfeit or substandard antimicrobial drugs: a review of the scientific evidence. J Antimicrob Chemother. 2007;60(2):214-236.

28. National Health Service [Internet]. Anabolic steroid misuse. 2018. Available from: https:/ / www.nhs.uk/conditions/anabolic-steroidmisuse/ Accessed 7 July 2019.

29. Jaberidoost M, Nikfar S, Abdollahiasl A, Dinarvand R. Pharmaceutical supply chain risks: a systematic review. DARU. 2013;21(1):1-7.

30. Visacri M, de Souza C, Shibata C, Granja S, de Marialva M, Gava P, Moriel P. Adverse drug reactions and quality deviations monitored by spontaneous reports. Saudi Pharm J. 2015;23(2):130-137.

Manuscript received on 15 July 2020. Revised version accepted for publication on 10 September 2020. 


\section{Medicamentos de calidad subestándar, falsificados y no registrados en América Latina, 2017-2018}

RESUMEN Objetivo. Evaluar todos los incidentes de medicamentos de calidad subestándar, falsificados y no registrados en 2017 y 2018 en América Latina, y determinar los tipos de productos afectados, los puntos de la cadena de suministro en los que se detectaron incidentes, las desviaciones de calidad identificadas en las muestras analizadas y las medidas regulatorias adoptadas por las autoridades.

Métodos. Se realizó una búsqueda exhaustiva en los sitios web de las autoridades regulatorias nacionales de América Latina y se identificaron todos los incidentes elegibles publicados durante 2017 y 2018. Se recogieron valores estandarizados de cada incidente conforme a variables predeterminadas: país, año, tipo de incidente, grupo terapéutico, cadena de suministro, medidas regulatorias, y datos de laboratorio.

Resultados. Se incluyeron en total 596 incidentes de 13 países (236 relacionados con calidad subestándar, 239 falsificados, 116 no registrados y 5 robados). Las categorías terapéuticas con mayor número de incidentes fueron los agentes antiinfecciosos, los medicamentos para el dolor/cuidados paliativos, las hormonas/ anticonceptivos, los medicamentos para las vías respiratorias y los medicamentos para trastornos mentales/ del comportamiento. Los lugares más comunes en los que se detectaron incidentes fueron los establecimientos comerciales, las farmacias, los servicios de salud y los fabricantes. Las fallas de calidad más recurrentes fueron deficiencia de los parámetros (fisicoquímicos, o el aspecto), etiquetado incorrecto, cantidad diferente del principio activo, presencia de partículas desconocidas y contaminación microbiológica. Las medidas regulatorias identificadas con más frecuencia fueron las alertas, los retiros e incautaciones del producto, y la prohibición de su comercialización, distribución o uso.

Conclusiones. En América Latina, los medicamentos de calidad subestándar, falsificados y no registrados continúan siendo un problema frecuente. Un desarrollo regulatorio avanzado se asocia con tasas más altas de detección y notificación de incidentes, y un conjunto más amplio de medidas en los países. La cadena de suministro farmacéutico es más vulnerable en su último eslabón. Las desviaciones de calidad identificadas en las muestras analizadas plantean graves riesgos para la salud pública.

Palabras clave Medicamentos falsificados; medicamentos de baja calidad; control de calidad; preparaciones farmacéuticas; comercialización de medicamentos; América Latina. 